\title{
PLANT SPECIATION: THE CLASSICAL APPROACH ${ }^{1}$
}

\author{
WARREN H. WAGNER, JR. \\ Department of Botany, The University of Michigan, Ann Arbor, Michigan 41409
}

Received September 14, 1982

A general biologist would have to be unusually naive to ask why there should be a special book on plant speciation. Just in case there is any question about it, Verne Grant's recent book should certainly settle the matter. Plants do indeed have a number of peculiarities in the way they go about things and all biologists should be aware of them, to say nothing of evolutionists. Although the new book is over a third again as long as its predecessor of the same name published in 1971 , the content has basically the same approach. The emphasis is on chromosomes, polyploidy, aneuploidy, apomixis, and hybridization, presumably because these are the classical elements in which plant speciation is believed to differ most from animal speciation. The topics are dealt with in chapters on populations and races, the nature of species, genetic and ecological species, evolutionary divergence, natural hybridization, polyploidy, aneuploidy, and specialized genetic systems, the last including apomixis, translocation heterozygosity, and natural triploidy. The bibliography is extensive, more than 900 references, of which over half were published in the 1950's and 1960's, the heyday of what was called plant biosystematics.

Species definition in plants has always been a problem. Grant solves it apparently to his satisfaction by favoring the rather pretentiously named and much argued "biological species," defined as reproductively isolated systems of breeding populations. Botanists especially have been troubled by this approach, which, as far as plants are concerned, seems simplistic. Actually Grant recognizes what he calls five "types" of species - taxonomic (morphological, phenetic) species, biological (genetic) species, microspecies (agamospecies), successional species or paleospecies, and biosystematic species (ecospecies, coenospecies). He throws aside "taxonomic species" as being artificial and out of concordance with the natural units. This will not gain him friends in the fraternity of well trained, present-day taxonomists, who are concerned with embodying a wide array of evidence in their construction of species. Clearly Grant is interested primarily in breeding behavior as the most important criterion of speciation. A combina-

\footnotetext{
${ }^{1}$ Plant Speciation. 2nd ed. Verne Grant. Columbia University Press, 1981 . xii +563 pp. $\$ 40.00$ hard cover. $\$ 15.00$ paper bound.
}

tion of so-called biological, apomictic, and successional species yields his concept of "evolutionary species." The only trouble with this is the fact that in plants we have numerous taxonomic species made up of demes that are intersterile but otherwise hardly distinguishable and new examples are being discovered constantly which differ from each other only in compatibility factors, ploidal differences, and so on. On the contrary, other plant groups undergo wholesale interspecific hybridization and give viable offspring the success or failure of which depends apparently on ecological forces rather than crossability.

Certain words are used in confusing ways. The term "uniparental" suggests to me an inbreeding individual (sporophyte in seedplants, gametophyte in archegoniates), but is used by the author to mean clonal, i.e., reproducing asexually by seeds, spores, or by vegetative growth. Clonal populations are not parental in the sexual sense but are essentially "pieces" of the original, mere proliferations. The term root crown is confused with stump; what are actually stump sprouts are said to arise from root crowns. The author also seems to be unaware that much vegetative apomixis comes about by underground roots rather than stems; he mentions only rhizomes and tubers, thus neglecting the large fraction of cloneformers that propagate by roots, including trembling aspen, which he states reproduces by "suckers from the root crown." I found the author's use of the word "reticulate" to be especially confusing. It is used in two senses-for the products of hybridization and for convergent evolution. For example, taxonomic or$\operatorname{ders} \mathrm{A}, \mathrm{B}, \mathrm{C}$, and $\mathrm{D}$, are given as having "reticulate patterns of morphological characters" when we are actually dealing with what most workers would call parallelism, convergence, or homoplasy. In an unusually vague discussion of "reticulate evolution," the author seems to imply that convergence at levels higher than the species may be due to hybridization. I find it hard to believe, even on the level of species, that hybridization can cause genuine duplication of characters found in one or the other parent. In my experience there are rare exceptions to the rule that where two parents have different divergent homologous character states or apomorphies or one has the divergent condition of the same character and the other the primitive condition, all divergent conditions will be blunted. Unless they are actually shared by the parents, the hybrid characters are what I term "hemiapomorphies," compromises, intermediates.

In this book there are a number of seemingly un- 
digested citations of work by others accepted uncritically by the author. One of the most curious of these (taken from papers written in the 1930's) is that low frequency of polyploidy in woody dicotyledons may be a result of the "bottleneck" of narrow cambial cells that restrict chromosome number and chromosome size. (On the contrary, elsewhere in the same volume we read that many woody genera have high chromosome numbers.)

In a book on plant speciation the general biologist might expect to learn about speciation in such photosynthetic organisms as algae, bryophytes, and pteridophytes, but there is little indeed having to do with these groups. Even the special features of reproductive biology that characterize them and that would have particular bearing upon their speciation are not discussed. Of the non-seedplant groups, the ferns are mentioned more than the others, but even in the ferns there is little here on what is distinctive about their speciation processes. This is not necessarily a reflection on the book, however, as to many workers plants do mean seedplants, and there is, we must admit, far less knowledge of modes of speciation, and especially in bryophytes and algae, than in seedplants.

In comparing the contents of this book with what I take to be the emphasis of today's research on plant speciation, I find it to be somewhat old-fashioned. The question is whether such phenomena as cytogenetics and breeding behavior have in recent years contributed any new insights; indeed we may even question whether these phenomena are really at the fountainhead of plant speciation. Do they precede, coincide with, or follow basic divergent speciation? Today we are more concerned with the role of geographical isolation and how dispersal versus vicariance phytogeography fit into the picture. Why has speciation exploded in the tropics in comparison to temperate lands? There seems to be much more current interest in all phylogenetic characters and their significance in speciation rather than just in breeding systems and chromosome numbers. There is more and more emphasis on character divergence and shared divergent advancements as the essence of species diversification. Ironically Grant includes but little on the fascinating role of floral biology, in spite of his own very substantial contributions to this field. There is practically nothing on the impact of co-evolution in speciation, and, for that matter, ecological factors in general are treated very lightly. Why do some genera speciate into enormous numbers of closely related species and others remain essentially conservative with few, strongly divergent species? The rapidly burgeoning fields of phytochemistry are slighted here-secondary compounds and their po- tential roles in speciation, allozymes as clues to genetic variability, and so on. Grant touches on these topics occasionally but does not bring the modern literature on them to bear on the problems of plant evolution.

Today the classical methods of biosystematics are thoroughly embodied in modern systematics. In spite of Grant's belief that taxonomists' species are arbitrary, with few exceptions the species that we recognize today in modern manuals and monographs are solidly established on the basis of many facts, intrinsic and extrinsic, thanks to our teachers of the 1940's and 1950's, individuals like Anderson, Constance, Gilmour, Rollins, and Stebbins, who emphasized to us that we should be biologists first, systematists second, and that we should adopt a broad base of comparison and inclusive synthesis - "maximum information content." This is true not only of species as completed products but of the processes which produced them as well. True divergence in terms of many characters--geographical distribution, habitat, phenology, structure, physiology, chemistry-all participate in the process of speciation as well as our recognition and interpretation of taxa. In the absence of substantial divergence over the broad biological spectrum, such phenomena as polyploidy, aneuploidy, sexuality, and crossability may actually be trivial, mere "evolutionary noise," things that plants do that really don't amount to much in the big picture of speciation. Ordinary diploid, sexual, outbreeding populations shall inherit the earth; it is they that supply the fundamental divergences from the groundplans of their ancestors that underly plant speciation, not the polyploids, the apomicts, or the hybrids. The pillars of significant speciation are character polarities and character-state correlations as they bear upon the successful adaptations of divergent plant populations, grades and clades.

To write a book on plant speciation is a big order. To be truly comprehensive would be a formidable task indeed, and what Grant has done is to emphasize certain aspects of biosystematics of seedplants. This is the major value of the book: To summarize the viewpoints of what might be called the biosystematic period in the history of plant evolution and taxonomy. One will not find much here on the new horizons of the future, however. New challenges are neglected. The book provides an excellent example of the effort to apply the biological species concept to plants. As a reference work it will serve admirably; the bibliography alone will be of considerable use to evolutionists. For students of animal evolution especially this book will provide many vistas of some of the chromosomal and breeding characteristics that are found in plant populations. 